\title{
Gain control network conditions: the role of the inhibition
}

\author{
Eduardo Serrano ${ }^{1^{*}}$, Thomas Nowoty ${ }^{2}$, Rafael Levi ${ }^{3}$, Brian H Smith ${ }^{4}$, Ramón Huerta ${ }^{5}$ \\ From Twenty Second Annual Computational Neuroscience Meeting: CNS*2013 \\ Paris, France. 13-18 July 2013
}

During neural information processing, solving decision making problems or performing pattern recognition in any sensory modality, the brain can recognize objects as the same thing regardless of the stimulus intensity. The regulation of the internal representation under various levels of extrinsic stimulation is called gain control [1].

However, the precise mechanisms for achieving effective gain control in the brain are unknown. Based on our understanding of the existence and strength of connections in the insect olfactory system, we analyze whether conditions exist that would lead to controlled gain. The question we want to address is to determine whether is possible to design stable neural circuits made of excitatory and inhibitory neurons capable of controlling the internal representation of the external stimulus using only the network properties. Using a mean field approximation for the network activity, we show that there is a precise relationship of network parameters that can account for stable internal representation regardless of the external stimulus. Our findings conclude that the most important network parameters are the connections from the inhibitory population to the rest. This is consistent with experimental findings [2]. We also show that the connections from the excitatory

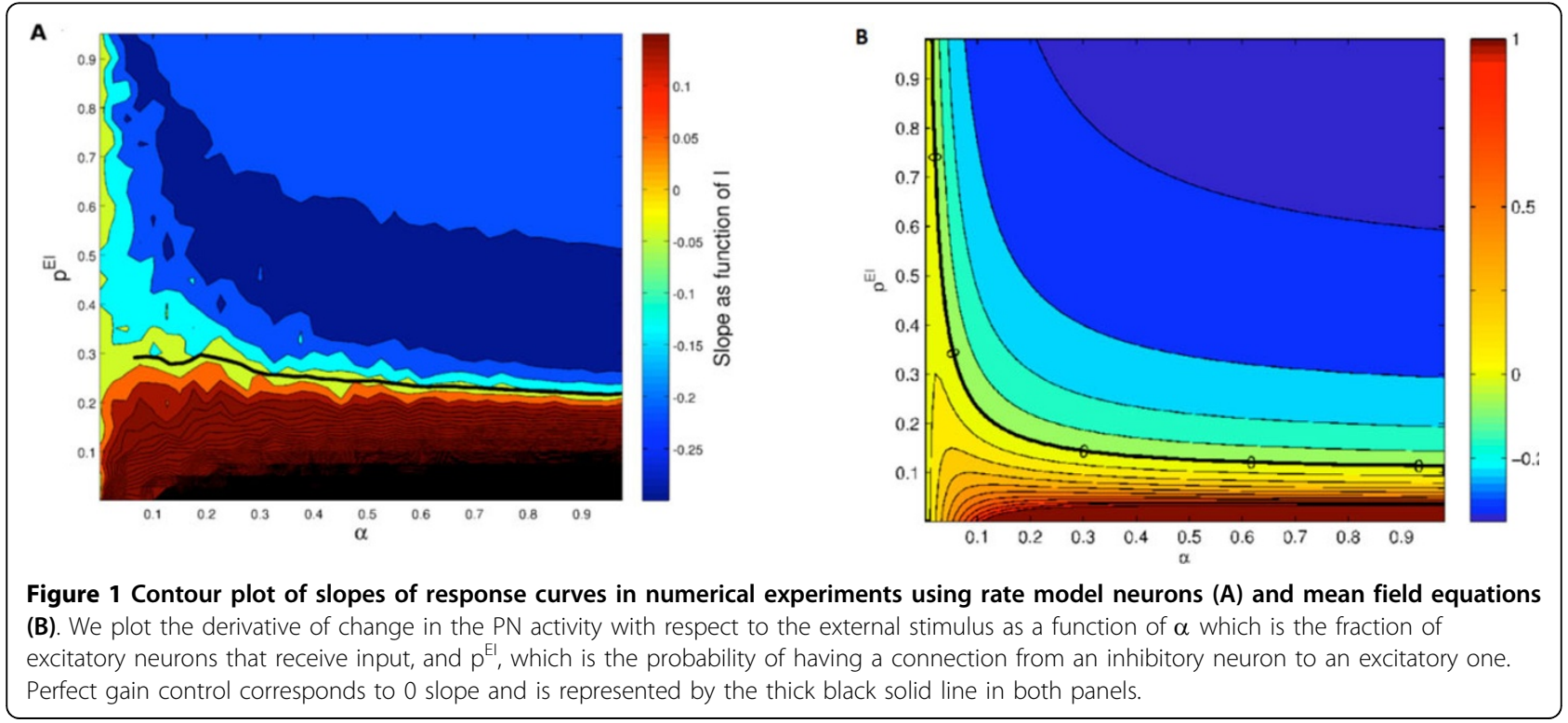

\footnotetext{
* Correspondence: eduardo.serrano@uam.es

'GNB, Department of Computer Science, Universidad Autónoma de Madrid, Madrid, Spain

Full list of author information is available at the end of the article
}

(c) 2013 Serrano et al; licensee BioMed Central Ltd. This is an Open Access article distributed under the terms of the Creative Commons 
population to the inhibitory one do not play an important role in gain control, suggesting that they can be freed for encoding purposes without damaging the operating response of the network to increasing levels of stimulation. Finally, we confirm that the gain control conditions derived from the mean field approximation are valid in simulations of firing rate models and Hodgkin-Huxley conductance based models.

\section{Acknowledgements}

This work was supported by MINECO TIN2012-30883, TIN-2010-19607 and IPT-2011-0727-02000

\section{Author details}

${ }^{1}$ GNB, Department of Computer Science, Universidad Autónoma de Madrid, Madrid, Spain. ${ }^{2}$ CCNR, Informatics, University of Sussex, Brighton, UK.

${ }^{3}$ Department of Neurobiology and Behavior, University of California, Irvine,

CA, USA. ${ }^{4}$ School of Life Sciences, Arizona State University, Tempe, AZ, USA.

${ }^{5}$ BioCircuits Institute, University of California San Diego, La Jolla, CA, USA.

Published: 8 July 2013

\section{References}

1. Salinas $E$, Thier P: Gain modulation: A major computational principle of the central nervous system. Neuron 2000, 27:15-21.

2. Olsen SR, Wilson RI: Lateral presynaptic inhibition mediates gain control in an olfactory circuit. Nature 2008, , 452: 956-960.

\section{Submit your next manuscript to BioMed Central} and take full advantage of:

- Convenient online submission

- Thorough peer review

- No space constraints or color figure charges

- Immediate publication on acceptance

- Inclusion in PubMed, CAS, Scopus and Google Scholar

- Research which is freely available for redistribution

Submit your manuscript at www.biomedcentral.com/submit 